GEOPHYSICAL RESEARCH LETTERS, VOL. 16, NO. 12, PAGES 1411-1414, DECEMBER 1989

\title{
A SLOW SEISMIC EVENT RECORDED IN PASADENA
}

\author{
Hiroo Kanamori
}

Seismological Laboratory, California Institute of Technology

Abstract. A prominent long-period wave with a duration of $2000 \mathrm{sec}$ or longer was recorded with a very-broadband system in Pasadena on June 18, 1988. This wave was not observed elsewhere, and is considered of local origin. The acceleration amplitude is $2.5 \times 10^{-5} \mathrm{~cm} / \mathrm{sec}^{2}$ in the northwest direction, with the vertical component less than $10 \%$ of the horizontal. The horizontal acceleration can be interpreted as due to a tilt of the ground of $2.5 \times 10^{-8}$ radians to the northwest. A slowly propagating pressure wave with an amplitude of about 15 mbars could be the cause of the tilt; however, there were no reports suggesting such pressure changes. A more likely cause is a slow tectonic event near Pasadena. The required magnitude of such a slow event is $M_{\mathrm{W}}=0,2$, and 4 , for a distance of $0.1,1$, and $10 \mathrm{~km}$ respectively. This event could be part of a tectonic episode associated with the larger earthquakes which occurred in southern California around this time, especially the December 3, 1988, Pasadena earthquake $\left(M_{\mathrm{L}}=4.9\right)$ which occurred six months later within $4 \mathrm{~km}$ of the Pasadena station.

\section{Introduction}

A very broadband seismographic system (WielandtStreckeisen Sensor plus Quanterra data logger) has been in operation at the Kresge Laboratory in Pasadena since December, 1987. This system, which will be referred to as the VBB system hereafter, is part of the IRIS (International Research Institution for Seismology) network and TERRAscope.

While examining the record of the June 18, 1988, Gulf of California earthquake $\left(M_{\mathrm{S}}=6.6\right)$ from the very-long-period (VLP) channel, we noticed a prominent long-period phase. This phase, labelled $X$ phase in Figure 1, is prominent only on the horizontal components, and at first appeared to be one of the multiple $\mathrm{G}$ waves from the event. However, a close examination of Figure 1 reveals that the arrival time of this phase does not correspond to that of expected surface wave trains. The $\mathrm{X}$ phase was also recorded with the Press-Ewing (30-100) instrument, the Benioff LP (1-90) instrument, and a ultra-long-period system (Pasadena No. 33) at the Kresge Laboratory (Figure 2). However, no signal was recorded on any of the short-period instruments. The VBB and PressEwing instruments are installed on the same pier. The Benioff instrument is located in a room adjacent to that which houses the Press-Ewing system. The ultra-long-period system (No. 33) is located very far from the Press-Ewing system, at the opposite end of the vault.

Copyright 1989 by the American Geophysical Union.

Paper number 89GL 03370 .

0094-8276/89/89GL-03370\$03.00

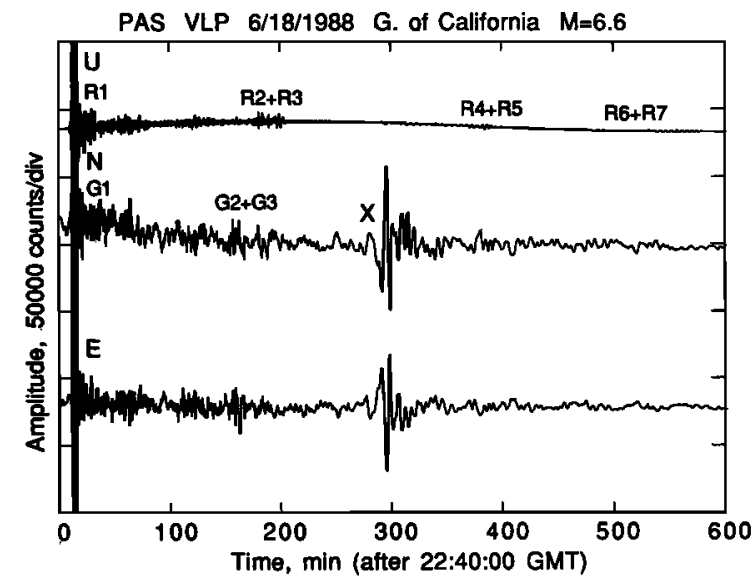

Fig. 1. Very-long-period (VLP) seismograms of the Gulf of California earthquake $\left(M_{\mathrm{S}}=6.6\right)$ of June 18,1988 . The response of the instrument is flat in velocity over a period range of 20 to $360 \mathrm{sec}$. In this range the gain is $1.66 \times 10^{8}$ counts $/(\mathrm{cm} / \mathrm{sec})$. At periods longer than $360 \mathrm{sec}$, it rolls off in proportion to $1 /$ (period) $^{2}$. Multiple surface waves are indicated on the trace. The slow event is marked by $\mathrm{X}$.

Since the phase was recorded with the VBB as well as other analog instruments, the recorded phase is not instrument noise but a real signal. The complete absence of short-period energy and the time of occurrence (8:00 pm local time, Saturday, June 18 ) preclude any man-made sources.

No such anomalous phase was recorded at Berkeley (Bruce Bolt, personal communication, 1988), or at the Piñon Flat Observatory (Duncan Agnew, personal communication, 1988) at about this time, which suggests that the $X$ phase is due to some local source rather than the Gulf of California earthquake. The small amplitude on the vertical component suggests that it could be due to tilt, rather than ground accelerations.

Slow seismic events have been reported by several investigators. The cause of these events includes: 1) Slip in soft sediments (Fukao, 1979; Sacks et al., 1978, and 1981), 2) Large-scale slumping both on land and seafloor (Kanamori and Given, 1982), 3) Episodic slip on a subduction thrust plane (Kanamori, 1972; Kanamori and Cipar, 1974; Kanamori and Anderson, 1975; Linde et al., 1988; Cifuentes and Silver, 1989), 4) Magma injection (Kanamori, et al. 1986), 5) Excitation by atmospheric pressure changes, 6) Episodic slip on weak faults along young transform faults (Kanamori and Stewart, 1976 and 1979; Beroza and Jordan, 1989), 7) Episodic slip on crustal detachment surfaces, 8) Unknown processes, possibly in the deep interior of the earth (Dziewonski and Gilbert, 1974). Some of the mechanisms are well established, but others are speculative. Although no 


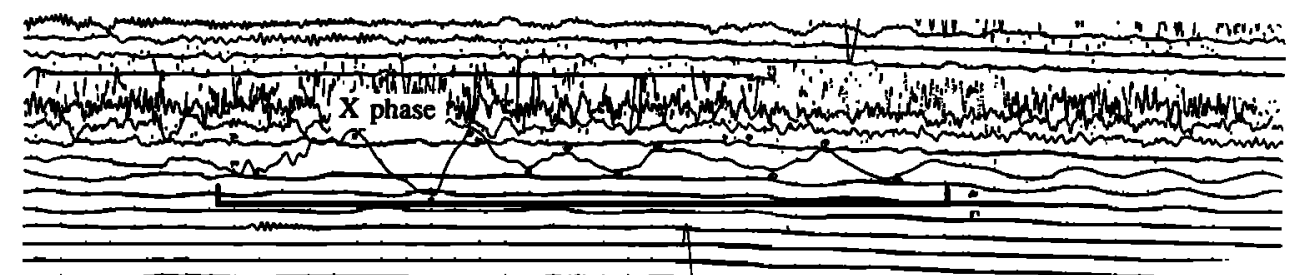

Press-Ewing N-S Component

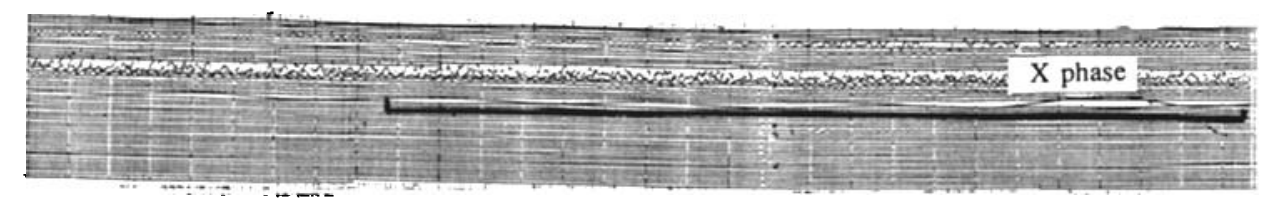

Benioff Long Period (1-90) E-W Component

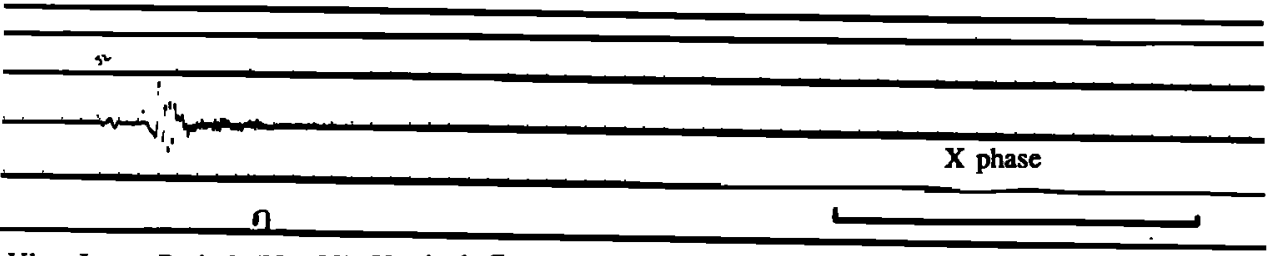

Ultra-Long Period (No 33) Vertical Component

Fig. 2. The $X$ phase (underlined) recorded by analog instruments at Pasadena (tick marks are given at every minute). Top: Press-Ewing (30-100) seismogram. Middle: Benioff Long-Period (1-90) seismogram. Bottom: Ultra-Long-Period seismogram. The peak response is at about 100 sec.

definitive conclusions can be obtained from data at one station, here we present the data and interpretation to alert other investigators who look at modern broadband data.

\section{Data}

Figure 3 shows acceleration records of the $X$ phase computed from the VLP records shown in Figure 1. The N-S and $\mathrm{E}-\mathrm{W}$ components are very coherent. As shown by the

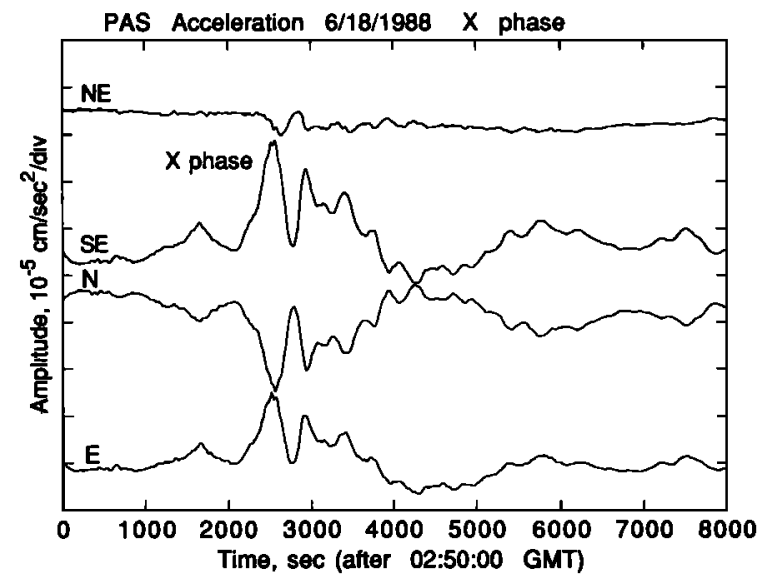

Fig. 3 . The $X$ phase on acceleration records computed from the VLP records shown in Figure 1. Rotated traces (NE-SW and SE-NW components) computed from N-S and E-W components are also shown. rotated traces in Figure 3, the acceleration is about $2.5 \times 10^{-8}$ $\mathrm{cm} / \mathrm{sec}^{2}$ to $\mathrm{SE}$, which corresponds to a tilt of $2.5 \times 10^{-8}$ radians to $\mathrm{NW}$, the magnitude of which is comparable to that of the earth tide. As shown by Figure 4, the spectrum of the acceleration record sharply falls off at $200 \mathrm{sec}$.

\section{Interpretation}

Although it is not possible to determine the cause of this signal from records at one station, we will examine two possibilities.

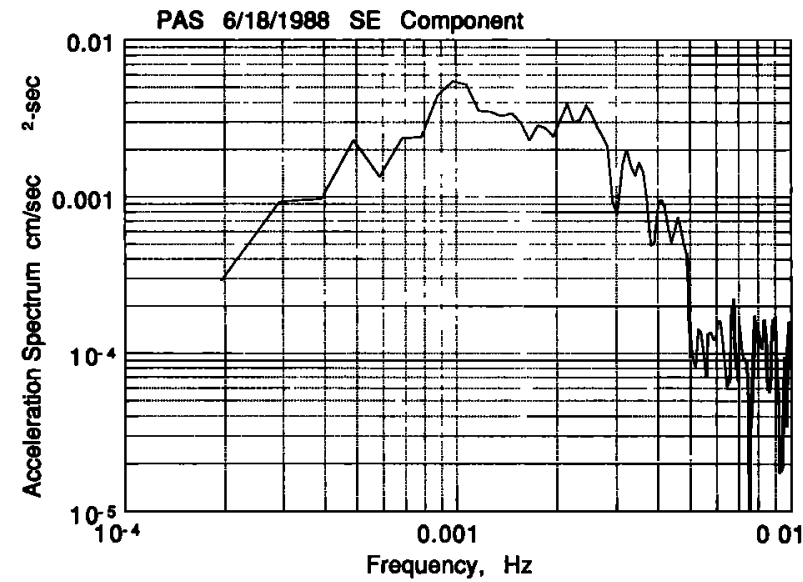

Fig. 4. The spectrum of the SE-NW component shown in Figure 3. 


\section{Pressure Change}

One possible source is a sudden burst of air motion in the Pasadena area. We consider a harmonic loading of an elastic half space by pressure $p_{0}$.

$$
p_{2 z}=p_{0} \cos [2 \pi(x-c t) / \lambda]
$$

where $x$ is the distance, $t$ is the time, $\lambda$ is the wavelength, and $c$ is the propagation velocity. Then the vertical component of the displacement at the surface, $w$, is given by (e.g. Jeffreys, 1959, p.198),

$$
w=-\left(p_{0} \lambda / 4 \pi \mu\right) \cos [2 \pi(x-c t) / \lambda]
$$

and the vertical acceleration is

$$
\ddot{w}=\left(\pi p_{0} c^{2} / \mu \lambda\right) \cos [2 \pi(x-c t) / \lambda]
$$

where $\mu$ is the rigidity of the crust.

$$
\varepsilon_{z x}=\frac{\partial w}{\partial x}=\left(p_{0} / 2 \mu\right) \sin [2 \pi(x-c t) / \lambda]
$$

The equivalent horizontal acceleration is

$$
\ddot{u}=g \varepsilon_{2 x}=\left(p_{0} g / 2 \mu\right) \sin [2 \pi(x-c t) / \lambda]
$$

From (4), we obtain $p_{0}=15$ mbars to yield the observed tilt of $2.5 \times 10^{-8}$ radians, where we assume $\mu=3 \times 10^{11} \mathrm{dyne} / \mathrm{cm}^{2}$. For the vertical acceleration to be negligible, we must have

$$
\left|\frac{\ddot{w}_{\max }}{\ddot{u}_{\max }}\right| \leq 0.1
$$

from which we obtain, using (3) and (5),

$$
c<90 \mathrm{~m} / \mathrm{sec}
$$

for $\lambda=50 \mathrm{~km}$.

Thus, a slow moving pressure wave in the Pasadena area with an amplitude of 15 mbars can explain the observed tilt without vertical acceleration. However, the required amplitude of the pressure change is so large that, if such a pressure change did occur, it would have been noticed by some local residents. The weather in Pasadena at the time was good, and there were no reports suggesting sudden pressure changes. Unfortunately, there were no barograph data available in the Pasadena area. Barograph data recorded at California State University Northridge (about $40 \mathrm{~km}$ from Pasadena) indicate no significant pressure changes larger than 1 mbar (Erhling Wang, written communication, 1988). Thus, the available evidence excludes sudden pressure changes as the cause of the $X$ phase.

\section{Slow Tilt.}

Another possible source is a slow tectonic event in the Pasadena area. If we assume a double-couple source with a seismic moment $M_{0}$, the maximum magnitude of tilt at a distance $r$ is approximately given by,

$$
\varepsilon=M_{0} / \pi \mu r^{3}
$$

In order to cause a tilt change of $2.5 \times 10^{-8}$, the required seismic moment of the event is about $2 \times 10^{16}$ dyne-cm
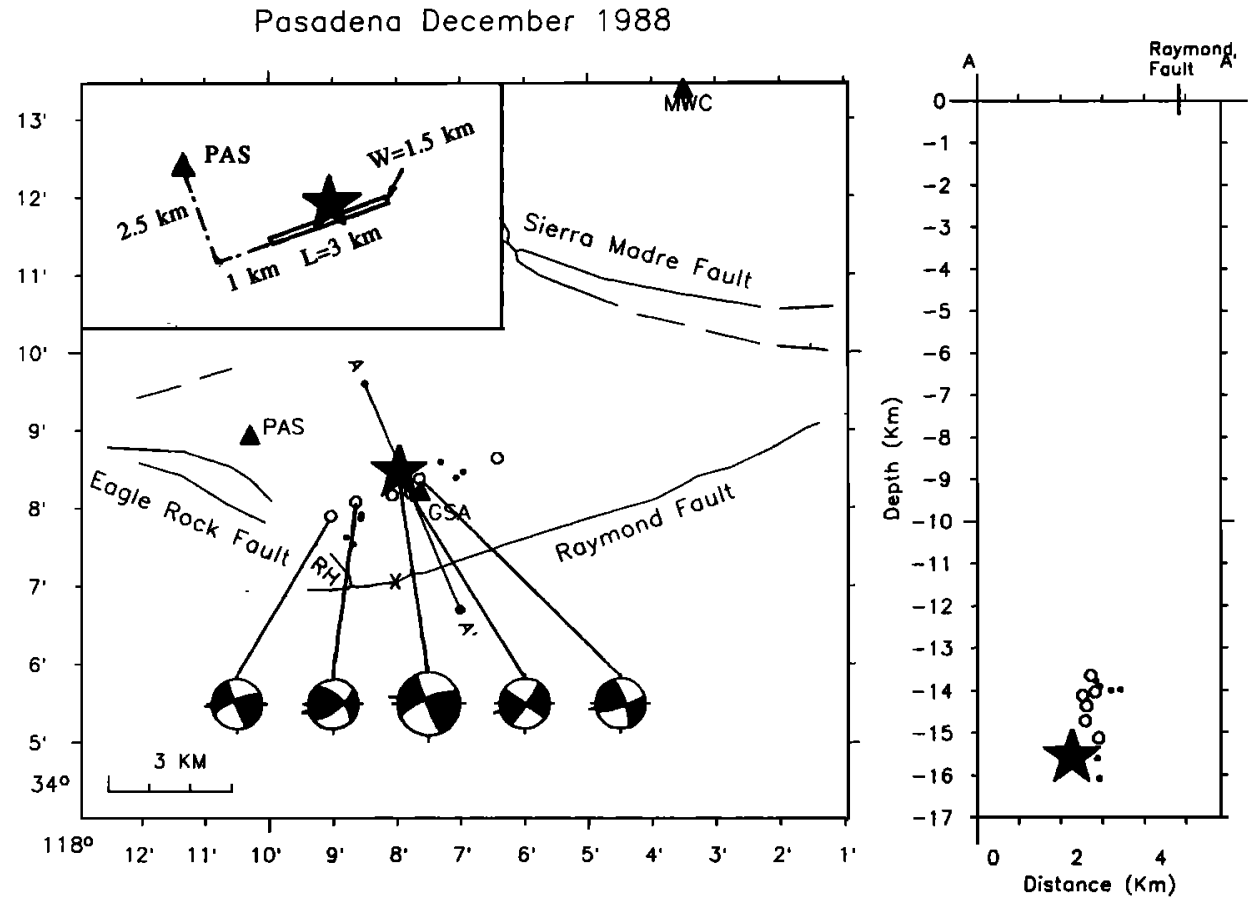

Fig. 5. The location and the mechanism of the 1988 Pasadena earthquake sequence (after Jones et al., 1989); the large asterisk indicates the main shock. The figure on the right shows the cross section taken along AA'. The inset shows the geometry of the fault model used for tilt calculation. 
$\left(M_{\mathrm{W}}=0\right), 2 \times 10^{19}$ dyne-cm $\left(M_{\mathrm{W}}=2\right)$, and $2 \times 10^{22}$ dyne-cm $\left(M_{\mathrm{W}}=4\right)$ for $r=0.1 \mathrm{~km}, 1 \mathrm{~km}$, and $10 \mathrm{~km}$ respectively. Although such slow deformation corresponding to an $M_{\mathrm{w}}=0$ to 4 event may occur in soft sediments or in shallow crust, we considered this possibility unlikely at the time of the event. However, the occurrence of the $M_{\mathrm{L}}=4.9$ Pasadena earthquake (December 3, 1988) 6 months later only $4 \mathrm{~km}$ from the this slow event could be part of a tectonic episode associated with the Pasadena earthquake.

As shown in Figure 5 (Jones et al.,1989), the Pasadena earthquake occurred at a depth of $16 \mathrm{~km}$ with a left-lateral mechanism on a $\mathrm{N} 80^{\circ} \mathrm{E}$ striking fault. We computed static displacement for several fault models using the program written by Okada(1985). If we put a slow event at the hypocenter of the Pasadena earthquake in the geometry shown in the inset of Figure 5, the tilt direction at the Pasadena station is opposite to the observed. The geometry of the fault model is taken from the mechanism of the Pasadena earthquake. This result is consistent with the nearfield displacement shown in figure 2 of Kanamori et al. (1989). Hence a slow slip at the hypocenter of the Pasadena earthquake is not likely to be the cause of the observed signal.

In contrast, if the same source is placed at the epicenter (i.e. at the surface), the tilt computed at the Pasadena station is in the NW direction, the same direction as the observed. A displacement of $0.3 \mathrm{~cm}$ is required on a fault plane of $3 \times 1.5$ $\mathrm{km}^{2}$ to yield the observed tilt of $2.5 \times 10^{-8}$ radians. Thus a slow slip which occurred near the surface, presumably in weak sediments, under the same tectonic stress that caused the Pasadena earthquake could be the cause of the slow event. However, our data are too limited to resolve the details.

It is also interesting to note that two relatively large earthquakes, the Garlock fault event, $M_{\mathrm{L}}=5.3$, on June 10 , 1988 , and the Upland earthquake, $M_{\mathrm{L}}=4.5$, on June 26,1988 , occurred within $100 \mathrm{~km}$ of Pasadena around the time of the slow event.

Acknowledgments. I thank Bruce Bolt and Duncan Agnew for sending me long-period records from Berkeley and Piñon Flats Observatories, respectively. Duncan Agnew also suggested to me the possibility that a slowly moving pressure wave was a possible cause of tilt. Erhling Wang, at California State University, Northridge, kindly sent me the barograph data for June, 1988, which turned out to be the only atmospheric pressure data available in the Los Angeles basin. Helpful suggestions given to me during coffee break discussions at the Seismological Laboratory provided the strong encouragement that enabled me to transform the seemingly nebulous data into this manuscript. This research was supported by U.S. Geological Survey grant number 14-0001-G1354. Contribution number 4776 from the Division of Geological and Planetary Sciences, California Institute of Technology, Pasadena, California 91125.

\section{References}

Beroza, G. C., and T. H. Jordan, Comparison of free oscillation excitation events with global seismicity: Evidence for silent earthquakes, EOS, 70, 397, 1989.
Cifuentes, I. L., and P. G. Silver, Low-frequency source characteristics of the Great 1960 Chilean earthquake, $J$. Geophys. Res. 94, 643-663, 1989.

Dziewonski, A. M., and F. Gilbert, Temporal variation of the seismic moment tensor and the evidence of precursive compression for two deep earthquakes, Nature, 247, 185$188,1974$.

Fukao, Y., Tsunami earthquakes and subduction process near deep-sea trenches, J. Geophys. Res., 84, 2303-2314, 1979.

Jeffreys, H., The Earth, 4th edition, Cambridge University Press, Cambridge, 1959.

Jones, L. M., K. E. Sieh, E. Hauksson, and L. K. Hutton, The December 3, 1988 Pasadena, California earthquake: Evidence for strike-slip motion on the Raymond fault, in press, Bull. Seismol. Soc. Am., 1989.

Kanamori, H., Mechanism of tsunami earthquakes, Phys. Earth Planet. Inter., 6, 346-359, 1972.

Kanamori, H., and D. L. Anderson, Amplitude of the Earth's free oscillations and long-period characteristics of the earthquake source, J. Geophys. Res., 80, 1075-1078, 1975.

Kanamori, H., and J. J. Cipar, Focal processes of the great Chilean earthquake May 22, 1960, Phys. Earth Planet. Int., 9, 128-136, 1974.

Kanamori, H., J. Mori, and T. H. Heaton, The December 3, 1988, Pasadena earthquake $\left(M_{\mathrm{L}}=4.9\right)$ recorded with the very-broad band system in Pasadena, in press, Bull. Seismol. Soc. Am., 1989.

Kanamori, H., G. Ekstrom, A. Dziewonski, and J. S. Baker, An anomalous seismic event near Torishima, Japan -- A possible injection event, EOS, Trans. Amer. Geophys. Union, 67, 1117, 1986.

Kanamori, H., and G. S. Stewart, Mode of the strain release along the Gibbs fracture zone, Mid-Atlantic ridge, $P$ hys. Earth Planet. Int., 11, 312-335, 1976.

Kanamori, H., and G. S. Stewart, A slow earthquake, Phys. Earth and Planet. Int., 18, 167-175, 1979.

Linde, A. T., K. Suyehiro, S. Miura, I. S. Sacks, and A. Takagi, Episodic aseismic slip, stress distribution and seismicity, Nature, 334, 513-515, 1988.

Okada, Y., Surface deformation due to shear and tensile faults in a half-space, Bull. Seismol. Soc. Am., 75, 1135-1154, 1985.

Sacks, I. S., S. Suyehiro, A. T. Linde and J. A. Snoke, Slow earthquakes and stress redistribution, Nature, 275, 599-602, 1978.

Sacks, I. S., A.T. Linde, J. A. Snoke, and S. Suyehiro, A slow earthquake sequence following the Izu-Oshima earthquake of 1978, in Earthquake Prediction, edited by D.W. Simpson and P. G. Richards, American Geophysical Union, pp. 617-628, Washington, D. C., 1981.

Hiroo Kanamori, Seismological Laboratory, California Institute of Technology 252-21, Pasadena, California 91125.

(Received August 1, 1989; revised October 20, 1989; accepted October 23, 1989.) 